\title{
Ranking important factors influencing organizational strategy in selecting distribution channels with the approach of FMCDM
}

\author{
Nima Soltanmohammad ${ }^{a^{*}}$, Mahmoud Modiri ${ }^{\mathrm{b}}$ and Kyamars Fathi Hafashjani ${ }^{\mathrm{b}}$
}

${ }^{a}$ Department of Industrial Management, Qazvin Branch, Islamic Azad University (IAU), Qazvin, Iran ${ }^{b}$ Department of Accounting \& Management, South Tehran Branch, Islamic Azad University (IAU), Tehran, Iran

\section{H R O N I C L E}

Article history:

Received June 10, 2013

Received in revised format

25 August 2013

Accepted September 262013

Available online

September 282013

Keywords:

Marketing strategy

Distribution channels

Fuzzy sets

$F M C D M$

FDAHP

FTOPSIS

\section{A B S T R A C T}

Marketing the network of organizations, including manufacturers, wholesalers, and retailers, that distributes goods or services to consumers is one of the most important decisions for marketing managers and producers. In this study, we identify and prioritize the factors, which affect marketing strategy in selecting distribution channels by using fuzzy multiple criteria decision-making (FMCDM). The proposed study uses Fuzzy Delphi Analytic Hierarchy Process to determine the weights of the criteria by decision makers and marketing strategies is ranked by Fuzzy Technique for Order Preference by Similarity to Ideal Solution (TOPSIS). Finally, the case study within a Kaleh Company (Dairy products) is performed and the results indicate that the "diversifying product" is the most important marketing strategies considered by experts.

(C) 2013 Growing Science Ltd. All rights reserved.

\section{Introduction}

Customer satisfaction is one of the primary objectives of businesses owners. Focus on the marketingmix including product, price, place and promotion is one of the best ways to achieve customer satisfaction. The importance of research on the marketing mix strategy is well recognized. Strategy is the ability and science of formulating, implementing, and evaluating cross functional decisions, which help any organization achieve its goal (David, 2012). 'Place' is concerned with various methods of transporting and storing goods, and then making them available for the customer. Getting the right product to the right place at the right time involves the distribution system. The choice of distribution method will depend on a variety of circumstances. Manufacturer or wholesaler must decide how to distribute their products. It will be more convenient for some manufacturers to sell to wholesalers who then sell to retailers, while others will prefer to sell directly to retailers or customers. Distribution needs to facilitate the sale and supply when one needs a product. In addition, this

* Corresponding author. Tel: +989124476045

E-mail addresses: nima.soltanmohammad@gmail.com (N. Soltanmohammad)

(C) 2013 Growing Science Ltd. All rights reserved. doi: $10.5267 /$ j.uscm.2013.09.004 
variable has to be compatible with other areas of marketing strategy such as product, price and promotion.

Kaleh is one of the dairy companies in Iran and has scattered its strategies for marketing its product such as variety of products and tastes, creating a need for the market by introducing new products and the capillary distribution, etc. However, the sales strategies are not clear officially and one of the primary questions on organization strategies in selecting distribution channels is how to present efficient and stable model, which could offer valid answers for the evaluated parameters and alternatives. The primary objective of this study is to identify and prioritize factors, which influence organizational strategy in selecting distribution channels. In addition, we try to identify sales strategies and prioritize them in Kaleh Co. and provide conditions for desirable customer satisfaction. The study tries to answer the following questions:

1.What are the criteria that improve sales strategies?

2. What is the relative importance (weight) of the identified criteria by using Fuzzy-Delphi-AHP method?

3.What is the prioritization of identified options by using FTOPSIS method?

\section{Literature Review}

Fuzzy multi-criteria decision-making approaches are proposed for the issues that consider uncertainty and imprecision. Analytical Hierarchy Process (AHP) introduced by Saati (1996), has been widely used in multi-criteria decision-making. TOPSIS method is also one of those useful multi-criteria decision making method for surveying issues in real world raised by Hwang \& Yoon (1981) for the first time. Chou and Lee (2013) classified success factors for commercialization of new products by using Delphi and Fuzzy AHP method and they analyzed the important factors. They identified four areas of decision making and prioritized 16 survey factors based on FAHP structure. Paksoy et al. (2012) developed the organization strategy of distribution channels management by using fuzzy hierarchy process (FAHP) and hierarchical fuzzy TOPSIS (HFTOPSIS) for evaluating and selecting among the five organization strategy models for distribution channel management of vegetable oil manufacturer. Finally, by using FAHP and HFTOPSIS, 'hybrid based strategy', which had the greatest desirability index, was found as the best choice.

Chen and Wang (2010) used a hybrid Fuzzy-Delphi-AHP approach to propose a more comprehensive framework with specific business elements and pointed out six performance indices for firms to adjust business strategy. Ic and Yurdakul (2009) used a hybrid of fuzzy AHP and TOPSIS multicriteria approaches along with elimination question to identify the feasible machining centers and ranked them. $\mathrm{Wu}$ and Tzeng (2009) proposed FMCDM approach for banking performance evaluation. They summarized the evaluation indexes associated with banking performance through expert questionnaires and calculated their weights by using FAHP and ranked them by three MCDM analytical tools of SAW, TOPSIS and VIKOR. Tzeng et al. (2010) used a hybrid model of Fuzzy AHP and TOPSIS for evaluation and selection of the best alternative in order to improve knowledge management. They calculated the weight of identified criteria and sub-criteria by using FAHP and ranked the alternatives by TOPSIS. Xu and Chen (2007) proposed a fuzzy multiple attribute group decision making model for determining appropriate air conditioning systems to be installed in a library. Wang (2008) applied fuzzy multi-criteria decision making approach to evaluate financial performance of domestic airlines in Taiwan. Chou (2007) utilized fuzzy MCDM method to deal with the marine transshipment container port selection problems. Jiang et al. (2008) proposed a method with fuzzy multi-granularity linguistic assessment information developed by for group decision making. Chang et al. (2006) utilized fuzzy linguistic quantifier to select supply chain partners at different phases of product life cycle. 


\section{Methodology}

\subsection{Concept of the fuzzy multiple criteria decision making}

Multi-criteria decision making (MCDM) comprises a finite set of alternatives where the decisionmakers has to select, to evaluate or to rank according to the weights of a finite set of criteria (attributes). There are various methods to deal with multi-criteria decision making problems, such as multiplicative exponential weighting (MEW), simple additive weighting (SAW), technique for ordering preference by similarity to ideal solution (TOPSIS), analytic hierarchy process (AHP) and so forth. It is unrealistic to assign a crisp value for a subjective judgment, especially when the information is vague or imprecise.

This study therefore introduces the fuzzy concept to use an interval or a range presenting the uncertainty and vagueness in the real world. Zadeh (1965 \& 1999) originally proposed a practical tool "fuzzy sets theory" to model subjective decision making processes. Bellman and Zadeh (1970) extended the decision making issues into fuzzy environments, numerous works coped with uncertain and vague problems by utilizing fuzzy sets theory. Fuzzy MCDM analysis has been widely utilized to tackle problems involving more than one attribute or alternative in ambiguous conditions. According to the literatures, FMCDM was mostly adopted in selection, evaluation and ranking, rarely used in the solutions of prediction or forecasting.

\subsection{Fuzzy Delphi analytic hierarchy process (FDAHP)}

The analytic hierarchy process (AHP) is an approach that is suitable for dealing with complex systems associated with making a choice from among several alternatives Saaty (1980). The AHP is based on the subdivision of the problem in a hierarchical form. In fact, the AHP helps organize the rational analysis a problem by splitting it into its single parts. The analysis then supplies an aid to the decision makers who, making several pair-wise comparisons, can appreciate the influence of the

considered elements in the hierarchical structure; the AHP can also give a preference list of the considered alternative solutions (Saaty, 1990-1996).

The AHP is a tool used for analyzing different kinds of social, political, economic and technological problems, and it uses both qualitative and quantitative variables. The fundamental principle of the analysis is the possibility of connecting information based on knowledge, to make decisions or previsions. The knowledge can be taken from experience or it can be derived from the application of other tools. Among different contexts in which the AHP can be applied, we may pay especial attention on creation of a list of priorities, the choice of the best policy, the optimal allocation of resources, the prevision of results and temporal dependencies, the assessment of risks and planning (Saaty, 1990). Although the AHP is to capture the expert's knowledge, the traditional AHP still cannot really reflect the human thinking style (Kahraman et al., 1988). The traditional AHP method is problematic in that it uses an exact value to express the decision maker's opinion in a comparison of alternatives (Wang \& Chen, 2007). In addition, AHP method is often criticized due to its use of unbalanced scale of judgments and its inability to adequately handle the inherent uncertainty and imprecision in the pair-wise comparison process (Deng, 1999). To overcome all these shortcomings, FDAHP was developed for solving the hierarchical problems. Decision makers usually find that it is more confident to give interval judgments than fixed value judgments. This is because usually he/she is unable to explicit his/her preference to explicit about the fuzzy nature of the comparison process. Delphi method is a technique for structuring an effective group communication process by providing feedback of contributions of information and assessment of group judgments to enable individuals to re-evaluate their judgments. Since its development in the 1960s at Rand Corporation, Delphi method has been widely used in various fields (Liu \& Chen, 2007; Cheng et al., 2009). On the other hand, Delphi method use crisp number and mean to become the evaluation criteria, these shortcomings might distort the experts' opinion. In order to deal with the fuzziness of human participants' 
judgments in traditional Delphi method, Ishikawa et al. (1993) posited fuzzy set theory proposed by Zadeh (1965) into the Delphi approach to improve time-consuming problems such as the convergence of experts' opinions presented by Hwang and Lin (1987). The FDM is a technique in which subjective data of experts are transformed into quasi-objective data using the statistical analysis and fuzzy operations. The main advantages of FDM (Kaufmann, 1988) are that it can reduce the numbers of surveys to save time and cost and it also includes the individual attributes of all experts. This paper proposes the use of FDAHP for determining the weights of the criteria which make implementation of sales strategies successful.

The relative fuzzy weights of the decision elements were calculated using the following three steps based on the FDM and aggregate the fuzzy weights to measure scores for the decision alternation. The mathematics concept adopted from Liu and Chen (2007). First, the triangular fuzzy numbers (TFNs) $\tilde{\mathrm{a}}_{\mathrm{ij}}$ were computed as defined in Eq. (1). In this work, the TFNs (shown as Fig.1) representing the pessimistic, moderate and optimistic estimate was used to represent the opinions of experts for each activity time (Zhu et al., 1999).

$a_{i j}=\left(\alpha_{i j}, \delta_{i j}, \gamma_{i j}\right)$

$\alpha_{i j}=\operatorname{Min}\left(\beta_{i j k}\right), k=1, \ldots, n$

$\delta_{i j}=\left(\Pi_{k=1}^{n} \beta_{i j k}\right)^{\frac{1}{n}}, k=1, \ldots, n$

$\gamma_{i j}=\operatorname{Max}\left(\beta_{i j k}\right), k=1, \ldots, n$

where $a_{i j} \leq \delta_{i j} \leq \gamma_{i j}, a_{i j}, \delta_{i j}, \gamma_{i j} \in\left[\frac{1}{9}, 1\right] \cup[1,9]$, and $a_{i j}, \delta_{i j}, \gamma_{i j}$ are obtained from Eqs. (2-4). $a_{i j}$ indicates the lower bound and $\gamma_{i j}$ indicates the upper bound. $\beta_{i j k}$ indicates the relative intensity of importance of expert $\mathrm{k}$ between activities $\mathrm{i}$ and $\mathrm{j} . \mathrm{n}$ is the number of experts in consisting of a group. Then fuzzy positive reciprocal matrix was obtained as: $\widetilde{A}=\left[\widetilde{a}_{i j}\right], \widetilde{a}_{i j} \times \widetilde{a}_{i j} \approx 1, \forall i, j=1, \ldots, n$, i.e. (Zhu et al., 1999).

$\tilde{A}=\left[\begin{array}{ccc}(1,1,1) & \left(\alpha_{12}, \delta_{12}, \gamma_{12}\right) & \left(\alpha_{13}, \delta_{13}, \gamma_{13}\right) \\ \left(1 / \gamma_{12}, 1 / \delta_{12}, 1 / \alpha_{12}\right) & (1,1,1) & \left(\alpha_{23}, \delta_{23}, \gamma_{23}\right) \\ \left(1 / \gamma_{13}, 1 / \delta_{13}, 1 / \alpha_{13}\right) & \left(1 / \gamma_{23}, 1 / \delta_{23}, 1 / \alpha_{23}\right) & (1,1,1)\end{array}\right]$

Lastly, calculate the relative fuzzy weights of the evaluation factors:

$\tilde{\mathrm{Z}}_{\mathrm{i}}=\left[\widetilde{\alpha}_{\mathrm{ij}} \otimes \ldots \otimes \widetilde{\alpha}_{i n}\right]^{1 / \mathrm{n}}, \widetilde{\mathrm{W}}_{\mathrm{i}}=\tilde{\mathrm{Z}}_{\mathrm{i}} \otimes\left(\tilde{\mathrm{Z}}_{\mathrm{i}} \oplus \ldots \oplus \tilde{\mathrm{Z}}_{\mathrm{n}}\right)^{-1}$

where $\widetilde{\alpha}_{1} \otimes \widetilde{\alpha}_{2} \cong\left(a_{1} \times a_{1}, \delta_{1} \times \delta_{2}, \gamma_{1} \times \gamma_{2}\right)$; the symbol $\otimes$ here denotes the multiplication of fuzzy numbers and the symbol $\bigoplus$ here denotes the addition of fuzzy numbers. $\widetilde{W}_{i}$ is a row vector in consist of a fuzzy weight of the its factor. $\widetilde{W}_{i}=\left(w_{1}, w_{2}, \ldots, w_{n}\right) i=1, \ldots, n$ and $W_{i}$ is a fuzzy weight of the it's factor.

\subsection{FTOPSIS method}

Technique for order preference by similarity to ideal solution (TOPSIS) is one of the useful multicriteria decision making (MCDM) techniques to manage real-world problems (Yoon \& Hwang, 1985). TOPSIS method was first proposed by Hwang and Yoon (1981). TOPSIS defines an index called similarity to the positive-ideal solution and the remoteness from the negative-ideal solution. Then, the method chooses an alternative with the maximum similarity to the positive-ideal solution 
(Hwang \& Yoon, 1981). It is often difficult for a decision-maker to assign a precise performance associated with an alternative for the attributes under consideration. The merit of using a fuzzy approach is to assign the relative importance of attributes using fuzzy numbers instead of precise numbers for suiting the real world in fuzzy environment. This section extends the TOPSIS to the fuzzy environment. This method is particularly suitable for handling the group decision-making problem under fuzzy environment. We briefly review the rationale of fuzzy theory before the development of fuzzy TOPSIS. In this paper, FTOPSIS method is implemented for determining the final ranking of the identified alternatives. The mathematics concept borrowed from Buyukozkan et al. (2007) and Wang and Chang (2007). FTOPSIS method is performed in the following steps.

Step 1: Assignment of ratings to the criteria and the alternatives.

Let us assume there are $J$ possible candidates called $\mathrm{A}=\left\{\mathrm{A}_{1}, \mathrm{~A}_{2}, \ldots, \mathrm{A}_{\mathrm{j}}\right\}$ which are evaluated against $n$ criteria $C=\left\{C_{1}, C_{2}, \ldots, C_{j}\right\}$. The criteria weights are denoted by $w_{i}(i=1, \ldots, m)$. The performance ratings of each decision maker $D_{k}(k=1, \ldots, k)$ for each alternative $A_{j}(j=1, \ldots, n)$ with respect to criteria $\mathrm{C}_{\mathrm{i}}\left(\mathrm{i}=1, \ldots, \mathrm{)}\right.$ are denoted by $\widetilde{\mathrm{R}}_{\mathrm{k}}=\widetilde{\mathrm{x}}_{\mathrm{ijk}}(\mathrm{i}=1, \ldots, \mathrm{m} ; \mathrm{j}=1, \ldots, \mathrm{n} ; \mathrm{k}=1, \ldots, \mathrm{k})$ with membership function $\mu_{\widetilde{R}_{\mathrm{k}}}(\mathrm{x})$.

Step 2: Compute aggregate fuzzy ratings for the criteria and the alternatives.

If the fuzzy ratings of all decision makers is described as triangular fuzzy number $\widetilde{\mathrm{R}}_{\mathrm{k}}=\left(\mathrm{a}_{\mathrm{k}}, \mathrm{b}_{\mathrm{k}}, \mathrm{c}_{\mathrm{k}}\right)$, $k=1, \ldots, K$, then the aggregated fuzzy rating is given by $\tilde{R}=(a, b, c), k=1, \ldots, K$, where;

$\mathrm{a}=\min _{\mathrm{k}}\left\{\mathrm{a}_{\mathrm{k}}\right\} \quad \mathrm{b}_{\mathrm{ij}}=\frac{1}{\mathrm{~K}} \sum_{\mathrm{k}=1}^{\mathrm{k}} \mathrm{b}_{\mathrm{k}} \quad \mathrm{c}=\max _{\mathrm{k}}\left\{\mathrm{c}_{\mathrm{k}}\right\}$

If the fuzzy rating and importance weight of the $\mathrm{k}^{\text {th }}$ decision maker are $\tilde{\mathrm{x}}_{\mathrm{ijk}}=\left(\mathrm{a}_{\mathrm{ijk}}, \mathrm{b}_{\mathrm{ijk}}, \mathrm{c}_{\mathrm{ijk}}\right)$ and $\widetilde{\mathrm{w}}_{\mathrm{ijk}}=\left(\mathrm{w}_{\mathrm{jk} 1}, \mathrm{w}_{\mathrm{jk} 2}, \mathrm{w}_{\mathrm{jk} 3}\right), \mathrm{i}=1, \ldots, \mathrm{m}, \mathrm{j}=1, \ldots, \mathrm{n}$ respectively, then the aggregated fuzzy ratings $\left(\tilde{\mathrm{x}}_{\mathrm{ij}}\right)$ of alternatives with respect to each criteria are given by $\tilde{x}_{i j}=\left(a_{i j}, b_{i j}, c_{i j}\right)$, where;

$\mathrm{a}_{\mathrm{ij}}=\operatorname{Min}_{\mathrm{k}}\left\{\mathrm{a}_{\mathrm{ijk}}\right\} \quad \mathrm{b}_{\mathrm{ij}}=\frac{1}{\mathrm{~K}} \sum_{\mathrm{k}=1}^{\mathrm{k}} \mathrm{b}_{\mathrm{ijk}} \quad \mathrm{c}_{\mathrm{ij}}=\operatorname{Max}_{\mathrm{k}}\left\{\mathrm{c}_{\mathrm{ijk}}\right\}$

The aggregated fuzzy weights $\left(\widetilde{\mathrm{w}}_{\mathrm{ij}}\right)$ of each criterion are calculated as $\widetilde{\mathrm{w}}_{\mathrm{ijk}}=\left(\mathrm{w}_{\mathrm{j} 1}, \mathrm{w}_{\mathrm{j} 2}, \mathrm{w}_{\mathrm{j} 3}\right)$, where:

$\mathrm{w}_{\mathrm{j} 1}=\operatorname{Min}_{\mathrm{k}}\left\{\mathrm{w}_{\mathrm{jk} 1}\right\} \quad \mathrm{w}_{\mathrm{j} 2}=\frac{1}{\mathrm{~K}} \sum_{\mathrm{k}=1}^{\mathrm{k}} \mathrm{w}_{\mathrm{jk} 2} \quad w_{j 3}=\operatorname{Max}_{k}\left\{w_{\mathrm{jk} 3}\right\}$

Step 3: Compute the fuzzy decision matrix.

The fuzzy decision matrix for the alternatives $(\widetilde{D})$ and the criteria $(\widetilde{W})$ is constructed as follows:

$$
\begin{aligned}
& \begin{array}{lllll}
C_{1} & C_{2} & \ldots & C_{n}
\end{array} \\
& \widetilde{D}=\begin{array}{c}
A_{1} \\
A_{2} \\
\cdots \\
A_{m}
\end{array}\left[\begin{array}{cccc}
x_{11} & x_{12} & \cdots & x_{1 n} \\
x_{21} & x_{22} & \cdots & x_{2 n} \\
\cdots & \cdots & \cdots & \cdots \\
x_{m 1} & x_{m 2} & \cdots & x_{m n}
\end{array}\right], i=1, \ldots, m ; j=1, \ldots, n \\
& \widetilde{\mathrm{w}}_{\mathrm{ijk}}=\left(\widetilde{\mathrm{w}}_{1}, \widetilde{\mathrm{w}}_{1}, \ldots, \widetilde{\mathrm{w}}_{\mathrm{n}}\right)
\end{aligned}
$$

Step 4: Normalize the fuzzy decision matrix.

The raw data are normalized using linear scale transformation to bring the various criteria scales into a comparable scale. The normalized fuzzy decision matrix $\tilde{R}$ is given by: 
$\tilde{R}=\left[\tilde{\mathrm{r}}_{\mathrm{ij}}\right]_{\mathrm{m} \times \mathrm{n}} \mathrm{i}=1, \ldots, \mathrm{m} ; \mathrm{j}=1, \ldots, \mathrm{n}$

where:

$\tilde{r}_{i j}=\left(\frac{a_{i j}}{C_{j}^{*}}, \frac{b_{i j}}{C_{j}^{*}}, \frac{c_{i j}}{C_{j}^{*}}\right)$ and $C_{j}^{*}=\max _{i} c_{i j} \quad$ (Benefit criteria)

$\tilde{\mathrm{r}}_{\mathrm{ij}}=\left(\frac{\mathrm{a}_{\mathrm{j}}^{-}}{\mathrm{c}_{\mathrm{ij}}}, \frac{\mathrm{a}_{\mathrm{j}}^{-}}{\mathrm{b}_{\mathrm{ij}}}, \frac{\mathrm{a}_{\mathrm{j}}^{-}}{\mathrm{a}_{\mathrm{ij}}}\right)$ and $a_{j}^{-}=\min _{i} a_{i j}$ (Cost criteria)

Step 5: Compute the weighted normalized matrix.

The weighted normalized matrix $\widetilde{V}$ for criteria is computed by multiplying the weights $\left(\widetilde{\mathrm{w}}_{\mathrm{j}}\right)$ of evaluation criteria with the normalized fuzzy decision matrix $\tilde{r}_{\mathrm{ij}}$ :

$\widetilde{V}=\left[\tilde{v}_{i j}\right]_{m \times n} \quad i=1,2, \ldots, m ; j=1,2, \ldots, n$

where:

$\tilde{v}_{\mathrm{ij}}=\tilde{r}_{\mathrm{ij}} \cdot \widetilde{w}_{\mathrm{j}}=\left(\frac{\mathrm{a}_{\mathrm{ij}}}{\mathrm{c}_{\mathrm{j}}^{*}} \cdot w_{j 1} ; \frac{\mathrm{b}_{\mathrm{ij}}}{\mathrm{c}_{\mathrm{j}}^{*}} \cdot w_{j 2} ; \frac{\mathrm{c}_{\mathrm{ij}}}{\mathrm{c}_{\mathrm{j}}^{*}} \cdot w_{j 3}\right) \quad$ (Benefit criteria)

$\tilde{\mathrm{v}}_{\mathrm{ij}}=\tilde{\mathrm{r}}_{\mathrm{ij}} \cdot \widetilde{\mathrm{w}}_{\mathrm{j}}=\left(\frac{\mathrm{a}_{\mathrm{j}}^{-}}{\mathrm{c}_{\mathrm{ij}}} \cdot \mathrm{w}_{\mathrm{j} 1} ; \frac{\mathrm{a}_{\mathrm{j}}^{-}}{\mathrm{b}_{\mathrm{ij}}} \cdot \mathrm{w}_{\mathrm{j} 2} ; \frac{\mathrm{a}_{\mathrm{j}}^{-}}{\mathrm{a}_{\mathrm{ij}}} \cdot \mathrm{w}_{\mathrm{j} 3}\right) \quad$ (Cost criteria)

Step 6: Compute the fuzzy positive ideal solution (FPIS) and fuzzy negative ideal solution (FNIS). The FPIS and FNIS of the alternatives are computed as follows:

$A^{*}=\left\{\tilde{v}_{1}^{*}, \tilde{v}_{2}^{*}, \ldots, \tilde{v}_{n}^{*}\right\}$ where $\tilde{v}_{i}^{*}=\operatorname{Max}_{i}\left\{\tilde{v}_{i j 3}\right\} \quad i=1, \ldots, m, j=1, \ldots, n$
$A^{-}=\left\{\tilde{v}_{1}^{-}, \tilde{v}_{2}^{-}, \ldots, \tilde{v}_{n}^{-}\right\}$where $\tilde{v}_{i}^{*}=\operatorname{Min}_{i}\left\{\tilde{v}_{i j 1}\right\} i=1, \ldots, m, j=1, \ldots, n$

Step 7: Compute the distance of each alternative from FPIS and FNIS.

The distance $\left(d_{i}^{*}, d_{i}^{-}\right)$of each weighted alternative $i=1, \ldots, m$ from the FPIS and the FNIS is computed as follows:

$S_{i}^{*}=\sum_{j=1}^{n} d_{v}\left(\tilde{v}_{\mathrm{ij}}, \tilde{v}_{\mathrm{j}}^{*}\right), \mathrm{i}=1, \ldots, \mathrm{m}$

$S_{i}^{-}=\sum_{j=1}^{n} d_{v}\left(\tilde{v}_{\mathrm{ij}}, \tilde{v}_{\mathrm{j}}^{-}\right), \mathrm{i}=1, \ldots, \mathrm{m}$

where $d_{v}(\tilde{a}, \tilde{b})$ is the distance measurement between two fuzzy numbers $\tilde{a}$ and $\tilde{b}$. the distance between them is computed as follows:

$d_{v}\left(\widetilde{M}_{1}, \widetilde{M}_{2}\right)=\sqrt{\frac{1}{3}\left[\left(a_{1}-a_{2}\right)^{2}+\left(b_{1}-b_{2}\right)^{2}+\left(c_{1}-c_{2}\right)^{2}\right]}$

Step 8: Compute the closeness coefficient $\left(\mathrm{CC}_{\mathrm{i}}\right)$ of each alternative.

The closeness coefficient $C C_{i}$ denotes the distances to the fuzzy positive ideal solution $\left(A^{*}\right)$ and the fuzzy negative ideal solution $\left(\mathrm{A}^{-}\right)$, simultaneously. The closeness coefficient of each alternative is calculated as: 
$\mathrm{CC}_{\mathrm{i}}=\frac{\mathrm{S}_{\mathrm{i}}^{-}}{\mathrm{S}_{\mathrm{i}}^{*}+\mathrm{S}_{\mathrm{i}}^{-}} \mathrm{i}=1, \ldots, \mathrm{m}$

Step 9: Rank the alternatives.

In step 9, the different alternatives are ranked according to the closeness coefficient $\mathrm{CC}_{\mathrm{i}}$ in decreasing order. The best alternative is closest to the FPIS and farthest from the FNIS.

\section{Results}

In this research, questionnaires were distributed between company's experts, and then some of the less important sub-criteria were removed. At last, according to Table 1 most effective criteria and sub-criteria have been identified.

\section{Table 1}

Effective criteria in marketing strategies

\begin{tabular}{|c|c|c|}
\hline Criteria & Sub-criteria & Symptoms \\
\hline \multirow{4}{*}{ Product } & Variety & $\mathrm{c}_{1}$ \\
\hline & Quality & $c_{2}$ \\
\hline & Brand & $c_{3}$ \\
\hline & Packing & $\mathrm{c}_{4}$ \\
\hline \multirow{3}{*}{ Price } & Pricing & $\mathrm{c}_{5}$ \\
\hline & Grant awards & $\mathrm{c}_{6}$ \\
\hline & Payment period & $\mathrm{c}_{7}$ \\
\hline \multirow{5}{*}{ Place (distribution) } & Capillary distribution & $\mathrm{c}_{8}$ \\
\hline & Coverage & $c_{9}$ \\
\hline & Products combination & $\mathrm{c}_{10}$ \\
\hline & Transport & $\mathrm{c}_{11}$ \\
\hline & Grant equipment & $\mathrm{c}_{12}$ \\
\hline \multirow{3}{*}{ Promotion } & Advertising products & $\mathrm{c}_{13}$ \\
\hline & Public relations & $\mathrm{c}_{14}$ \\
\hline & Customer Satisfaction & $\mathrm{c}_{15}$ \\
\hline
\end{tabular}

The weight of this sub-criteria calculated by using triangle Fuzzy-Delphi-AHP approach and prioritization between them was performed as shown in Table 2 and Fig.2.

\section{Table 2}

Fuzzy and non-fuzzy weight of criteria

\begin{tabular}{|c|c|c|c|c|c|c|}
\hline \multicolumn{2}{|l|}{ Sub-Criteria } & \multicolumn{3}{|c|}{ Fuzzy weight $\left(W_{i}\right)$} & \multirow{2}{*}{$\begin{array}{c}\text { Non-fuzzy weight } \\
0.083\end{array}$} & \multirow{2}{*}{$\frac{\text { Ranking }}{1}$} \\
\hline Capillary distribution & $\mathrm{c}_{8}$ & 0.062 & 0.083 & 0.111 & & \\
\hline Customer Satisfaction & $\mathrm{c}_{15}$ & 0.060 & 0.080 & 0.107 & 0.080 & 2 \\
\hline Quality & $\mathrm{c}_{2}$ & 0.061 & 0.080 & 0.105 & 0.080 & 3 \\
\hline Transport & $\mathrm{c}_{11}$ & 0.059 & 0.079 & 0.107 & 0.080 & 4 \\
\hline Coverage & $\mathrm{c}_{9}$ & 0.059 & 0.079 & 0.105 & 0.079 & 5 \\
\hline Grant equipment & $\mathrm{c}_{12}$ & 0.055 & 0.073 & 0.098 & 0.073 & 6 \\
\hline Variety & $\mathrm{c}_{1}$ & 0.054 & 0.071 & 0.095 & 0.071 & 7 \\
\hline Packing & $\mathrm{c}_{4}$ & 0.053 & 0.069 & 0.091 & 0.070 & 8 \\
\hline Public relations & $\mathrm{c}_{14}$ & 0.047 & 0.064 & 0.091 & 0.065 & 9 \\
\hline Brand & $\mathrm{c}_{3}$ & 0.042 & 0.064 & 0.092 & 0.063 & 10 \\
\hline Pricing & $\mathrm{c}_{5}$ & 0.046 & 0.061 & 0.082 & 0.061 & 11 \\
\hline Products combination & $\mathrm{c}_{10}$ & 0.041 & 0.055 & 0.076 & 0.055 & 12 \\
\hline Payment period & $\mathrm{c}_{7}$ & 0.038 & 0.051 & 0.068 & 0.051 & 13 \\
\hline Grant awards & $\mathrm{c}_{6}$ & 0.033 & 0.047 & 0.065 & 0.047 & 14 \\
\hline Advertising products & $\mathrm{c}_{13}$ & 0.029 & 0.043 & 0.061 & 0.042 & 15 \\
\hline
\end{tabular}




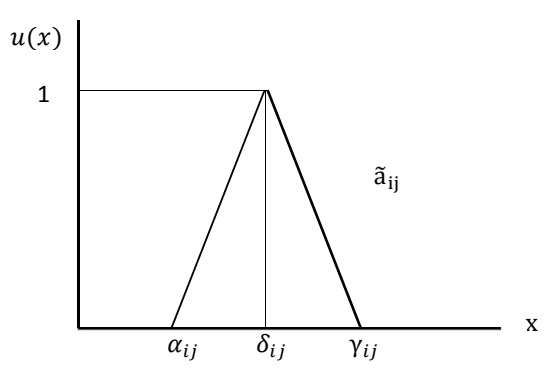

Fig. 1. The membership functions of the Fuzzy Delphi method

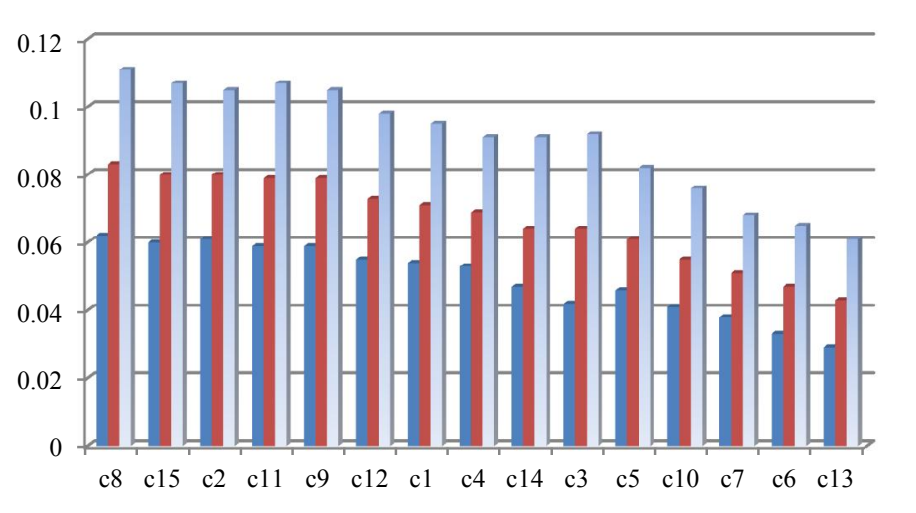

Fig. 2. Chart column of fuzzy weight for customer needs

After calculating and weighting criteria through the FDAHP process, FTOPSIS method was used to rank alternatives. Marketing strategies in Kaleh Co. have been shown in Table 3. In addition, the hierarchy structure has been shown in Fig. 3 .

Table 3

Marketing strategies in Kaleh Co

\begin{tabular}{cc}
\hline Symptoms & Alternatives \\
\hline A1 & Minimizing the costs to the lowest possible level \\
A2 & Reducing the market share to strengthen product \\
A3 & Wide promotion \\
A4 & Keep some distribution channels and delete the rest \\
A5 & Wide distribution \\
A6 & Make the best distribution system \\
A7 & Reducing the price \\
A8 & determining the price to penetrate in the market \\
A9 & Diversifying product and brand \\
A10 & Product Development \\
A11 & Offering a main product \\
\hline
\end{tabular}

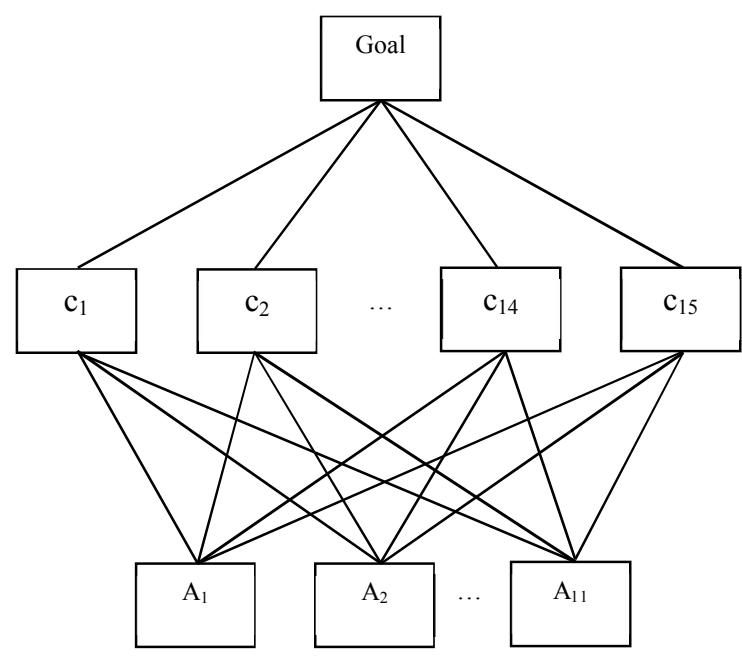

Fig. 3. The hierarchy structure between goal, criteria, sub-criteria and alternatives 
The decision makers evaluated the alternatives with respect to each attribute by using the linguistic arguments and sets up the decision matrix in Table 4.

Table 4

Linguistic terms for ranking the alternatives

\begin{tabular}{cc}
\hline Definition & Triangular fuzzy number \\
\hline Very Low (VL) & $(0,0,1)$ \\
Low (L) & $(0,1,3)$ \\
Medium Low (ML) & $(1,3,5)$ \\
Medium (M) & $(3,5,7)$ \\
Medium High (MH) & $(5,7,9)$ \\
High (H) & $(7,9,10)$ \\
Very High (VH) & $(9,10,10)$ \\
\hline
\end{tabular}

Then we computed the weighted decision matrix and determined the FPIS and FNIS. The distance of each alternative to the FPIS and FNIS, respectively, is calculated and the relative closeness coefficients are determined, given in Table 5 and Fig. 4. The alternatives are ranked accordingly, and we get $A_{9}>A_{10}>A_{3}>A_{6}>A_{5}>A_{11}>A_{8}>A_{1}>A_{4}>A_{2}>A_{7}$. The best alternative is $A_{9}$. Because of the space limitation, we do not show the step by step computation.

Table 5

Ranking marketing strategies in Kaleh Co.

\begin{tabular}{ccccc}
\hline Symptoms & FPIS & FNIS & CC $_{\mathrm{i}}$ & Ranking \\
\hline $\mathrm{A}_{9}$ & 0.687 & 0.858 & 0.555 & 1 \\
$\mathrm{~A}_{10}$ & 0.668 & 0.799 & 0.545 & 2 \\
$\mathrm{~A}_{3}$ & 0.677 & 0.792 & 0.539 & 3 \\
$\mathrm{~A}_{6}$ & 0.690 & 0.767 & 0.526 & 4 \\
$\mathrm{~A}_{5}$ & 1.216 & 0.849 & 0.411 & 5 \\
$\mathrm{~A}_{11}$ & 0.975 & 0.574 & 0.370 & 6 \\
$\mathrm{~A}_{8}$ & 0.987 & 0.561 & 0.362 & 7 \\
$\mathrm{~A}_{1}$ & 0.997 & 0.561 & 0.360 & 8 \\
$\mathrm{~A}_{4}$ & 1.021 & 0.523 & 0.339 & 9 \\
$\mathrm{~A}_{2}$ & 1.014 & 0.484 & 0.323 & 10 \\
$\mathrm{~A}_{7}$ & 1.040 & 0.471 & 0.312 & 11 \\
\hline
\end{tabular}

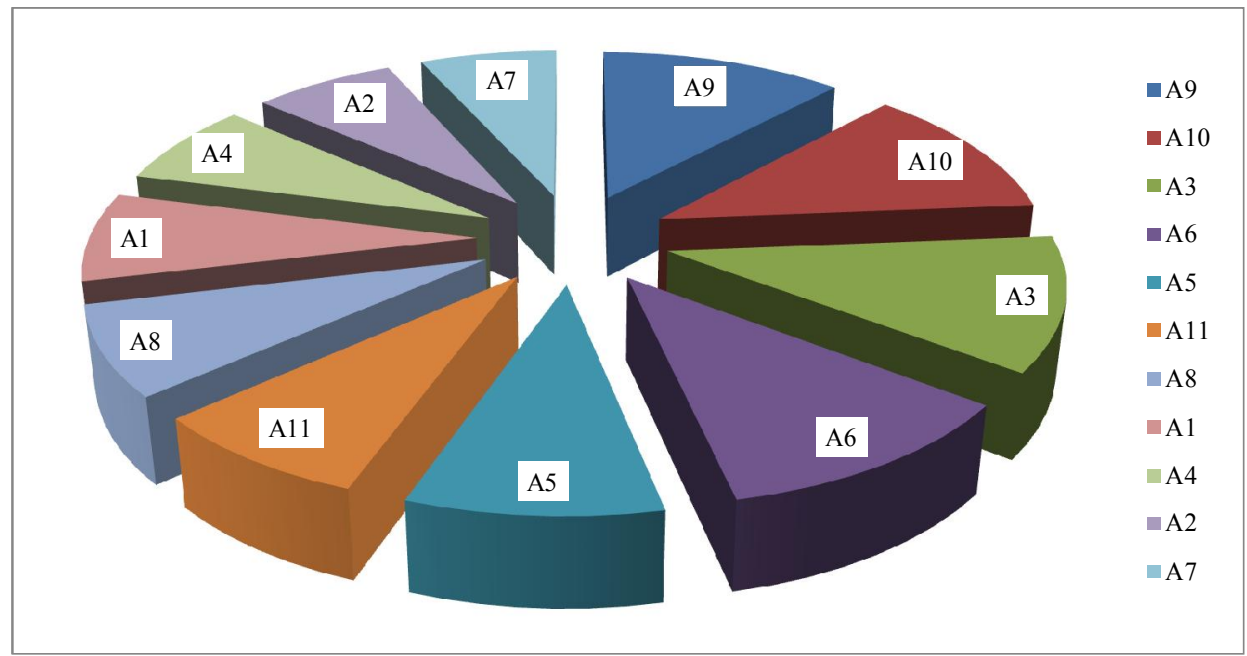

Fig. 4. Ranking marketing strategies in Kaleh Co. 


\section{Conclusion}

We have discussed that there are various methods in field of strategies prioritization. The main drawbacks of existing methods were as follow: losing significant part of gathered information during the process, less attention to uncertainly conditions, imprecise formulation of the complex and uncertain nature of the issues and engaging the mind of decision maker by a large number of contribution factors in decision making. In this paper, FMCDM (Fuzzy multi-criteria decision making) method was used in order to increase the reliability of decision makings. These techniques evaluate different alternative with respect to variety of criteria in different scale. Another important advantage of the FMCDM method is the capability of analyzing both quantitative and qualitative criteria at the same time. Using Fuzzy TOPSIS method to consider ambiguous situations, was the novelty of this paper.

The case study within a Kaleh Co. (Dairy products) was done and Fuzzy Delphi AHP method was used to determine the weights of the criteria by decision makers and then the rank of marketing strategies was determined by Fuzzy TOPSIS. According to the research findings, 'product' had the most influence in marketing strategies and distribution, promotion and price were in the next priority. Also, according to the calculated weight, the most important sub-criteria were as follows: (1) capillary distribution, (2) customer satisfaction and (3) quality. The result of prioritization of marketing strategies in Kaleh Co. showed that the most important strategies were diversifying product and brand, product development and promotion.

\section{Acknowledgement}

The authors would like to thank the anonymous referees for the comments on earlier version of this paper.

\section{References}

Bellman, R.E., \& Zadeh, L.A. (1970). Decision making in a fuzzy environment. Management Science, 17(4), 141-164.

Buyukozkan, G., Feyziog lu, O., \& Nebol, E. (2007). Selection of the strategic alliance partner in logistics value chain. International Journal of Production Economics, 113(1), 148-158.

Chang, S.L., Wang, R.C., \& Wang, S.Y. (2006). Applying fuzzy linguistic quantifier to select supply chain partners at different phases of product life cycle. International Journal of Production Economics, 100, 348-359.

Cheng, J. H., Lee, C. M., \& Tang, C. H. (2009). An application of fuzzy Delphi and fuzzy AHP on evaluating wafer supplier in semiconductor industry. WSEAS Transactions on Information Science and Applications, 6(5), 756-767.

Chen, M. K., \& Wang, S. C. (2010). The use of a hybrid fuzzy-Delphi-AHP approach to develop global business intelligence for information service firms.Expert Systems with Applications, 37(11), 7394-7407.

Cho, J., \& Lee, J. (2013). Development of a new technology product evaluation model for assessing commercialization opportunities using Delphi method and fuzzy AHP approach. Expert Systems with Applications, 40(13), 5314-5330.

Chou, C.C. (2007). A fuzzy MCDM method for solving marine transshipment container port selection problems. Applied Mathematics and Computation, 186, 435-444.

David, F. R. (2012).Strategic Management: A Competitive Advantage Approach, Concepts and Cases, $14^{\text {th }}$ Ed.

Deng, H. (1999). Multi-criteria analysis with fuzzy pair-wise comparison. International Journal of Approximate Reasoning, 21, 215-31.

Hwang CL, \& Yoon K. (1981). Multiple attributes decision making methods and applications. Berlin: Springer; 1981. 
Hwang, C.L, \& Lin, M.L. (1987). Group decision making under multiple criteria. Berlin: Springer.

İç, Y. T., \& Yurdakul, M. (2009). Development of a decision support system for machining center selection. Expert systems with Applications, 36(2), 3505-3513.

Ishikawa, A., Amagasa, M., Shiga, T., Tomizawa, G., Tatsuta, R., \& Mieno, H. (1993). The Max-Min Delphi method and fuzzy Delphi method via fuzzy integration. Fuzzy sets and systems, 55(3), 241253.

Jiang, Y. P., Fan, Z. P., \& Ma, J. (2008). A method for group decision making with multi-granularity linguistic assessment information. Information Sciences, 178(4), 1098-1109.

Kahraman, C., Ruan, D., \& Doğan, I. (2003). Fuzzy group decision-making for facility location selection. Information Sciences, 157, 135-153.

Kaufmann, A., \& Gupta, M.M. (1988). Fuzzy mathematical models in engineering and management science. Amsterdam: North-Holland; 1988.

Kuo, M.S., Tzeng, G.H., \& Huang, W.C. (2007). Group decision making based on concepts of ideal and anti-ideal points in fuzzy environment. Mathematical and Computer modeling, 45(3/4), 324 339.

Liu, Y.C., \& Chen, C.S. (2007). A new approach for application of rock mass classification on rock slope stability assessment, Engineering geology, 89, 129-43.

Liu, Y.C, \& Chen C.S. (2007). A new approach to classification base on association rule mining, Journal of Decision Support System, 42, 674-689.

Paksoy, T., Pehlivan, N.Y., \& Kahraman, C. (2012). Organizational strategy development in distribution channel management using fuzzy AHP and hierarchical fuzzy TOPSIS. Expert Systems with Applications, 39, 2822-2841.

Saaty, T.L. (1980). The analytic hierarchy process. New York: McGraw-Hill; 1980.

Saaty, T.L., \& Vargas, L.G. (1990). The analytic hierarchy process series. Pittsburgh: University of Pittsburgh.

Saaty, T.L. (1996). Decision Making with Dependence and Feedback: The Analytic Network Process. RWS publications, Pittsburg.

Tsaur, S.H., Chang, T.Y., \& Yen, C.H. (2002). The evaluation of airline service quality by fuzzy MCDM. Tourism Management, 23, 107-115.

Tseng, M. L. (2011). Using a hybrid MCDM model to evaluate firm environmental knowledge management in uncertainty. Applied Soft Computing,11(1), 1340-1352.

Wang, Y.J. (2008). Applying FMCDM to evaluate financial performance of domestic airlines in Taiwan. Expert Systems with Applications, 34, 1837-1845.

Wang, T. C., \& Chen, Y. H. (2007). Applying consistent fuzzy preference relations to partnership selection. Omega, 35(4), 384-388.

Wang, T. C., \& Chang, T.-H. (2007). Application of TOPSIS in evaluating initial training aircraft under a fuzzy environment. Expert Systems with Applications, 33(4), 870-880.

$\mathrm{Wu}$, H.Y, Tzeng, G.H, Chen, Y.H. (2009). A fuzzy MCDM approach for evaluating banking performance based on Balanced Score card. Expert Systems with Applications, 36, 10135-10147.

$\mathrm{Xu}$, Z.S., \& Chen, J. (2007). An interactive method for fuzzy multiple attribute group decision making. Information Sciences, 177, 248-263.

Yang, T., \& Hung, C.-C. (2007). Multiple-attribute decision making methods for plant layout design problem. Robotics and Computer-Integrated Manufacturing, 23(1), 126-137.

Yoon, K., \& Hwang, C. L. (1985). Manufacturing plant location analysis by multiple attribute decision making: Part I-single-plant strategy. International Journal of Production Research, 23(2), 345-359.

Zadeh, L.A. (1965). Fuzzy sets. Information and Control, 8(3), 338-353.

Zadeh, L.A. (1999). Some reflections on the anniversary of Fuzzy Sets and Systems, Fuzzy Sets and Systems, 100, 1-3.

Zhu K.J., Jing Y., \& Chang D.Y. (1999). A discussion on extent analysis method and applications of Fuzzy-AHP. European Journal of Operational Research, 116, 450-456. 